Personalidade Acadêmica Homenageada:

Augustus B. Cochran III (Agnes Scott College)

\title{
COMPLIANCE E POLÍTICAS PÚBLICAS: CAMINHO PREVENTIVO NO COMBATE DE CRIMES NO ÂMBITO EMPRESARIAL?
}

\section{COMPLIANCE AND PUBLIC POLICIES: PREVENTIVE WAY IN FIGHTING CRIMES IN BUSINESS?}

JAQUELINE MARIA RYNDACK

Advogada. Mestranda em Direito Empresarial e Cidadania pelo Centro Universitário Curitiba - UNICURITIBA. Especialista em Ministério Público - Estado Democrático de Direito, na área de concentração em Direito Penal, Fundação Escola do Ministério Público do Paraná -FEMPAR. E-mail: ryndack.jaqueline@hotmail.com

\section{FÁBIO ANDRÉ GUARAGNI}

Professor Orientador. Procurador de Justiça no MP-PR. Doutor e Mestre em Direito das Relações Sociais (UFPR). Professor de Direito Penal Econômico no Mestrado do UNICURITIBA. Professor de Direito Penal: FEMPAR, EMAP, CERS.E-mail: guaragni@mppr.mp.br

\section{RESUMO}

Em meio há inúmeros escândalos de desvio de capitais que têm sido noticiados constantemente em diversas formas de mídia, a sociedade busca melhora desse cenário. No presente trabalho, após delimitar o Compliance como uma das quatro pilastras da Governança Corporativa, busca-se apresentar a utilização do Compliance como um instrumento de política pública de combate de crimes no âmbito empresarial. Por meio da utilização do método dedutivo, com a utilização de pesquisa bibliográfica, iniciamos o presente conceituando Compliance e expondo a sua 
Personalidade Acadêmica Homenageada:

Augustus B. Cochran III (Agnes Scott College)

implantação por meio de políticas públicas, de modo a apresentá-lo como um caminho preventivo no combate de crimes no âmbito empresarial. Desse modo, definiu-se Compliance como a adoção de práticas e procedimentos, códigos de ética e condutas internas, estabelecimento de treinamentos e cursos, processos e controles internos, além da adoção de mecanismos de identificação de desvios de conduta e de monitoramento, da feitura de auditorias internas e externas, canais de denúncia, entre outros atos e ações que atribuam e criem um padrão valorativo e comportamental da empresa. É notório que as empresas estão preocupadas com que a sua marca esteja associada à confiança, credibilidade e que seja um diferencial, e a própria sociedade busca empresas que transpareçam serem éticas e responsáveis, com a ideia do "Princípio Responsabilidade". O Compliance, enquanto caminho preventivo no combate de crimes no âmbito empresarial, sob a ótica das políticas públicas, quebra a concepção da res pública utilizada em benefício de seleto grupo, transformando esse novo olhar para contemplar que a 'coisa do povo' seja de fato e em benefício do povo enquanto coletividade. Ao tratar do Compliance, notadamente no âmbito da empresa como caminho preventivo no combate de crimes, seja ela pública ou privada, sua implantação gera uma maior transparência nas relações internas, uma igualdade de tratamento entre acionistas, canais céleres aos quais é possíveis apontar eventuais irregularidades sem a ocorrência da identificação do denunciante, entre outras situações. Um programa de Compliance deve alterar a cultura criminógena dentro e fora da empresa, prevenindo ilícitos penais e extra penais, desse modo, o Compliance deve ultrapassar a esfera privada da empresa e atingir modificar a cultura da sociedade.

PALAVRAS-CHAVE: Compliance; Políticas Públicas; Governança Corporativa; Empresa.

\section{REFERÊNCIAS}

BARACAT, Eduardo Milléo; ZAGONEL, Marina. Compliance e Assédio Moral nas 
Personalidade Acadêmica Homenageada:

Augustus B. Cochran III (Agnes Scott College)

relações de emprego: análise do programa da Companhia Paranaense de Energia COPEL. Percurso - ANAIS DO VIII CONBRADEC. Curitiba, v. 04, n. 27, 2018, p. 455 - $477 . \quad$ Disponível em: <http://revista.unicuritiba.edu.br/index.php/percurso/article/view/3182/371371714>. Acesso em: 09/01/2019.

BERTONCCELLI, Rodrigo de Pinho. Compliance. in CARVALHO, André Castro; BERTONCCELLI, Rodrigo de Pinho; ALVIM, Tiago Cripa; VENTURINI, Otavio (coords.). Manual de Compliance. Rio de Janeiro: Forense, 2019.

BRASIL. Lei Complementar № 101, de 4 de maio de 2000. Estabelece normas de finanças públicas voltadas para a responsabilidade na gestão fiscal e dá outras providências.

Disponível em: <http://www.planalto.gov.br/ccivil_03/leis/lcp/lcp101.htm>. Acesso em: 23/05/2019.

. Lei № 1.079, de 10 de abril de 1950. Define os crimes de responsabilidade e regula 0 respectivo processo de julgamento. Disponível em: <http://www.planalto.gov.br/ccivil_03/leis/1079.htm>. Acesso em: 23/05/2019.

. Lei № 8.429, de 2 de junho de 1992. Dispõe sobre as sanções aplicáveis aos agentes públicos nos casos de enriquecimento ilícito no exercício de mandato, cargo, emprego ou função na administração pública direta, indireta ou fundacional e dá outras providências. Disponível em: <http://www.planalto.gov.br/ccivil_03/leis//8429.htm>. Acesso em: 23/05/2019.

Lei № 12.527, de 18 de novembro de 2011. Regula o acesso a

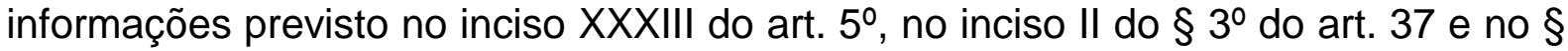
$2^{\circ}$ do art. 216 da Constituição Federal; altera a Lei no 8.112, de 11 de dezembro de 1990; revoga a Lei oㅜ 11.111, de 5 de maio de 2005, e dispositivos da Lei oㅡ 8.159, de 8 de janeiro de 1991; e dá outras providências. Disponível em: <http://www.planalto.gov.br/ccivil_03/_ato2011-2014/2011/lei//12527.htm>. Acesso em: 23/05/2019.

Lei № 12.846, de $1^{\circ}$ de agosto de 2013. Dispõe sobre a responsabilização administrativa e civil de pessoas jurídicas pela prática de atos contra a administração pública, nacional ou estrangeira, e dá outras providências. Disponível em: <http://www.planalto.gov.br/ccivil_03/_ato2011-2014/2013/lei//12846.htm>. Acesso em: 23/05/2019.

. Lei № 13.303, de 30 de junho de 2016. Dispõe sobre a responsabilização administrativa e civil de pessoas jurídicas pela prática de atos contra a administração pública, nacional ou estrangeira, e dá outras providências. Disponível em: <http://www.planalto.gov.br/ccivil_03/_ato2015-2018/2016/lei//13303.htm>. Acesso em: 23/05/2019. 
Personalidade Acadêmica Homenageada:

Augustus B. Cochran III (Agnes Scott College)

CARDOSO, Débora Motta. Criminal compliance na perspectiva da lei de lavagem de dinheiro. São Paulo: LiberArs, 2015.

GALBRAITH, John Kenneth. A economia das fraudes inocentes: verdades para o nosso tempo. Trad. Paulo Anthero Soares Barbosa. São Paulo: Companhia das Letras, 2004.

GUARAGNI, Fábio André. Compliance Como Instrumento de Combate à Corrupção. 2017. (48m01s). Disponível em: $<$ https://www.youtube.com/watch?v=bFhTowjSW9c>. Acesso em: 23/05/2019.

JONAS, Hans. O Princípio Responsabilidade: Ensaio de uma ética para a civilização tecnológica. Trad. Marijane Lisboa e Luiz Barros Montez. $2^{\underline{a}}$ reimpressão. Rio de Janeiro: Contraponto, 2006.

KNOERR, Fernando Gustavo; MARTINS, José Alberto Monteiro. O Poder de Polícia e o Compliance no Estado de Direito e sua Influência na Lei Anticorrupção (Lei $n$. 12.846 de $1^{\circ}$ de agosto de 2013). Revista Jurídica - UNICURITIBA. Curitiba, v. 2, n. 43, 2016.

LOPES, Rénan Kfuri. O Compliance como instrumento de política pública de combate à corrupção. Disponível em: <http://www.rkladvocacia.com/o-compliancecomo-instrumento-de-politica-publica-de-combate-corrupcao/>. Acesso em: 23/05/2019.

RIBEIRO, Marcia Carla Pereira; DINIZ, Patrícia Dittrich Ferreira. Compliance e Lei Anticorrupção nas Empresas. Revista de Informação Legislativa. Senado Federal. Brasília, ano 52, n. 205, p. 87-105, jan/mar. 2015. Disponível em: $<w w w 12 . s e n a d o . l e g . b r / r i l / e d i c o e s / 52 / 205 / r i l \_v 52 \_n 205 \_p 87 . p d f>$. Acesso em: $14 / 01 / 2019$.

RYNDACK, Jaqueline Maria; GUARAGNI, Fábio André. Governança Corporativa, Compliance e a Responsabilização Criminal do Chief Compliance Officer: uma interface da relação entre Direito e Sustentabilidade. In LIMA, Renata Albuquerque; ENGELMANN, Wilson; TYBUSCH, Jerônimo Siqueira (Coord.). Direito e Sustentabilidade I. Florianópolis: CONPEDI, 2018, p. 238 - 258. Disponível em: $<$ http://conpedi.danilolr.info/publicacoes/34q12098/0009mby0/iO3E7rPk548JU69F.p df>. Acesso em: 23/05/2019.

RYNDACK, Jaqueline Maria; LIMA, Sandra Mara Maciel de. Uma análise da aplicação do compliance em clínicas e hospitais de Curitiba. in Anais do Simpósio de Pesquisa e Iniciação Científica do UNICURITIBA. Disponível em: $<$ www.even3.com.br/anais/spic/124254-UMA-ANALISE-DA-APLICACAO-DOCOMPLIANCE-EM-CLINICAS-E-HOSPITAIS-DE-CURITIBA>. Acesso em: 05/01/2019. 
Personalidade Acadêmica Homenageada:

Augustus B. Cochran III (Agnes Scott College)

TRIBUNAL DE JUSTIÇA DO PARANÁ. Processo no 20110003365-0 - Decisão monocrática. $2^{\mathrm{a}}$ Turma Recursal, Cascavel. Relator Luiz Claudio Costa. Julgado em: 07/04/2011. Publicado em: 07/04/2011. Disponível em: <https://portal.tjpr.jus.br/jurisprudencia/j/32011000336500201104072/Decis\%C3\%A3 ०\%20monocr\%C3\%A1tica-20110003365-0\#>. Acesso em: 06/03/2019. 